\title{
Study of the regularity of the process of decomposition of apatite with sulfuricacid at the boilingpoint of the solution
}

\author{
C Rauf F. Sabirov, ${ }^{+}{ }^{+}$Alexey F. Makhotkin, Yury N. Sakharov, \\ Igor A. Makhotkin, Ilia Yu. Sakharov, and Roman V. Durnik \\ Department of Chemical Plants Equipment. Kazan National Research Technological University. \\ K. Marx St., 68. Kazan, 420015. Russia.E-mail: Sabirov.9090@mail.ru
}

*Supervising author; ${ }^{+}$Corresponding author Keywords: kinetics, boilingpoint, phosphoricacid, sulfuricacid, apatite, technology.

\begin{abstract}
Experimental research of the kinetics of the decomposition process of Kovdorsky apatite with a size $=$ $0.16 \mathrm{~mm}$ with sulfuric acid in a $1 \mathrm{dm}^{3}$ batch reactor. Phosphoric acid with the concentration of $68.6 \% \mathrm{wt}$ and the sulfuric acid with the concentration of $12.3 \% \mathrm{wt}$ in stoichiometric amount was introduces at the beginning of the process. The process was carried out at a ratio of liquid and solid phases $2.5: 1$ respectively at the boiling point of the mixture equal to $136{ }^{\circ} \mathrm{C}$. The observing the progress was carried out according to the method of joint designation of sulfuric and phosphoric acids by titrimetric analysis. With methyl orange and then phenolphthalein 2 titration jumps were recorded, the first of which corresponded to the neutralization of sulfuric acid to $\mathrm{Na}_{2} \mathrm{SO}_{4}$ and phosphoric acid to $\mathrm{NaH}_{2} \mathrm{PO}_{4}$, the second to the neutralization of $\mathrm{NaH}_{2} \mathrm{PO}_{4}$ to $\mathrm{Na}_{2} \mathrm{HPO}_{4}$. The change in temperature of the reaction mixture was fixed during the process using a mercury thermometer. In the analysis of the derived experimental values of specified parameters that the boiling point decreases from 136 to $133.1{ }^{\circ} \mathrm{C}$ within 50 minutes during the process. A comparison of the reported values with the concentration values of sulfuric and phosphoric acids measured during the process shows that the change in boiling point of the reaction mixture is proportional to the change in the concentrations of sulfuric and phosphoric acids. This model is a closed system that provides thermal insulation and no loss of material balance. Thus, the kinetics of the decomposition of apatite with sulfuric acid at the boiling point can be monitored by the temperature change under specified conditions.
\end{abstract}

\section{References}

[1] B.A. Kopylev. Extraction phosphoric acid technology. Leningrad: Chemistry. 1981. P.99-101. (russian)

[2] I.P. Muhlenov. Fundamentals of chemical technology. Moscow: High School. 1991. 463p. (russian)

[3] N.S. Torocheshnikov, A.I. Rodionov, N.V. Keltsev, V.N. Klushin. Environmental protection technique. Moscow: Chemistry. 1981. 512p. (russian)

[4] L.P. Grosheva. Tehnologiya inorganic substances: Collection of laboratory works No.2. N. Novgorod: Novgorod State University. 2007. 29p. (russian)

[5] Yu.N. Sakharov, A.F. Makhotkin, I.A. Makhotkin. Generalization of the laws of the kinetics of the decomposition of phosphate and apatite with solutions of phosphoric and sulfuric acids. Bulletin of Kazan Technological University. 2015. Vol.22. No.18. P.37-39. (russian) 